Research Article

\title{
Effect of Tool Geometry on Mechanical and Micro-structural properties of Friction Stir Welding of Al-alloy
}

\author{
Biswajit Parida $^{\dot{A}^{*}}$, M M Mohapatra $^{\dot{\mathrm{B}}}$ and Pankaj Biswas ${ }^{\dot{\mathrm{A}}}$ \\ ${ }^{\dot{A}}$ Mechanical Engineering, IIT Guwahati, India \\ ${ }^{\mathrm{B}}$ Mechanical and Industrial Engineering, IIT Roorkee, India
}

Accepted 10 January 2014, Available online 01 February 2014, Special Issue-2, (February 2014)

\begin{abstract}
The present study is on the development of friction stir welding (FSW) of commercial grade Al-alloy to study the effect of tool geometry on mechanical and micro-structural properties. The proposed research will include experiments related to the effect of FSW optimum process parameter on weldability of Al alloy. The present paper has been subdivided in to two different sections: 1. Study of Mechanical properties and 2. Study of micro-structural properties. Section-1 describes the effect of tool geometry on tensile strength and distribution of micro-hardness in different zones of FSW weld specimen and section-2 contains the microstructure characterization of different zones of friction stir welds. Two types of tool geometries have been used in the present work such as straight cylindrical (SC) and tapered cylindrical (TC). Tensile results shown an increase in ductility for welded joints compared to base metal. SC tools shown better strength compared to TC tools.
\end{abstract}

Keywords: FSW, weldability, mechanical properties, tensile strength, micro-hardness, microstructure.

\section{Introduction}

The history of joining metals goes back several millennia, with the earliest examples of welding from the Bronze Age and the Iron Age. From that time the process of welding gone through several modifications, world wars caused a major surge in the use of welding processes, with the various military powers attempting to determine which of the several new welding processes would be best. Many sophisticated welding methods for different alloys of variety applications are available now. Friction Stir Welding (FSW) is a solid state welding method without using filler material. The process was invented by The Welding Institute (TWI), Cambridge, UK and patented in 1991. In which the joined material is plasticized by heat generated by friction between the surface of the plates to be welded and the contact surface of a special tool, which is composed of two main parts; shoulder and pin. The process is shown in Fig. 1.

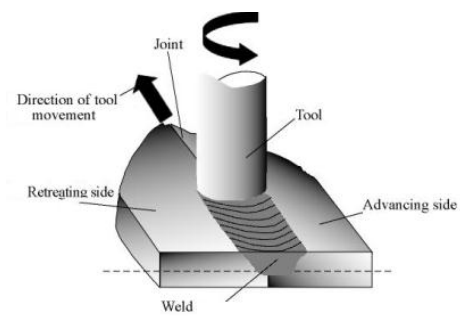

Fig. 1 Friction Stir Welding Process.

*Corresponding author: Biwajit Parida

DOI: http://dx.doi.org/10.14741/ijcet/spl.2.2014.16
Shoulder is responsible for the generation of heat and for containing the plasticized material in the weld zone, while pin mixes the material of the components to be welded, thus creating a joint. This allows for producing defect-free welds characterized by good mechanical properties.

Wang and Liu (2004) studied the Friction stir welding of aluminum: In this, the Aluminum plates were friction stir welded at various rotation speeds $(850-1860 \mathrm{rpm})$ and travel rates of 30 to $160 \mathrm{~mm} / \mathrm{min}$ with welding forces ranging from 2.5 to $10 \mathrm{MPa}$ using different dimension welding heads. From the experiments it has found that dimensions of the welding head are critical to produce sound weld. $10 \%$ higher micro-hardness is obtained than the parent metal.

Ceschini et. al. (2007) examined microstructure, tensile and fatigue properties of AA6061FSW joints. They found that the comminution effect induced on the ceramic reinforcement led to a significant reduction of the reinforcement particles area and to their roundness. The matrix interparticles hardness showed a decrease, from the base material to the middle line of the FSW zone. Welding process led to a decrease of both the proof strength and ultimate tensile strength respect to the base material. The elongation to failure increased of about $64 \%$. The cyclic stress response curves showed evidence of progressive hardening to failure of the FSW composite and a progressive softening of the base material, at all cyclic strain-amplitudes.

Attallah et. al. (2007) carried out quantitative microstructural studies using optical and electron microscopy in AA5251 aluminium alloy. This is to 
determine the grain size and inter-metallic particle distributions in various locations of welds to study their influence on the microhardness. They found that the TMAZ/WN strength was primarily controlled by grain boundary strengthening. Xie et. al. (2007) joined $6 \mathrm{~mm}$ thick $\mathrm{g}-\mathrm{Zn}-\mathrm{Y}-\mathrm{Zr}$ plate under a tool rotation rate of 800 $\mathrm{rpm}$ and a traverse speed of $100 \mathrm{~mm} / \mathrm{min}$. During FSW, fine and equiaxed recrystallized grains of 6.8 micrometer were generated and the strengths and elongation of the joints were only slightly lower than the parent material. The joining efficiency was high.

Scialpi A., et al. (2007) studied the influence of shoulder geometry on microstructure and mechanical properties of friction stir welded 6082 aluminum alloy: In this work, the tool analysis has been carried out on AA 6082 T6 $1.5 \mathrm{~mm}$ thick sheets and the welding process was carried out rotating the tool at $1810 \mathrm{rpm}$ and at a feed rate of $460 \mathrm{~mm} / \mathrm{min}$. Three types of shoulder geometries have been taken into consideration. From the experiments it was concluded that TFC tool (tool with fillet and cavity) crown is the best in terms of crown quality. Fujii H., et al. (2006)studied the effect of tool shape of friction stir welded aluminum alloys. Boz M. \& Kurt A. (2004)studied the influence of Stirrer Geometry on Bonding and Mechanical Properties in friction stir welding process: In this, the effect of stirrer geometry on the weldability and mechanical properties of welded aluminum plates using FSW process was investigated. Fonda et. al. (2007) investigated the microstructural evolution in FSW of 2195 Al-Li alloy. They observed large, undeformed grains far from the tool to the refined grains near the tool. It suggested that there was a single grain subdivision mechanism operating across all the regions around the tool.

Simar et. al . (2008) studied the effect of the welding speed on the microstructure and mechanical properties of friction stir welded Al alloys. They found occurrence of dissolution of the precipitates and formation of coarse precipitates in HAZ. The strain hardening capacity of the WZ is larger than that of the HAZ. Cabibbo M., et al. (2007) studied the microstructure and mechanical property studies of AA6056 friction stir welded plates: In this work, the author has investigated the microstructure and mechanical properties of a friction stir welded 6056-T6 aluminum alloy plate by using polarized optical and transmission electron microscopy techniques. Sarsilmaz $F$. \& Caydas U. (2008) studied the statistical Analysis on Mechanical Properties of Friction Stir Welded AA1050/AA5083 couples: In this, the effect of friction stir welding parameters on the mechanical properties of Aluminum alloys as investigated. Sakthivel T., et. al. (2008) studied the effect of Welding Speed on Mechanical Properties of Friction-stir Welded Aluminum: In this present investigation aluminum welds were made at various welding speed using the friction stir welding technique by using a hardened steel FSW tool. Adamowski J. \& Szkodo M. (2007) studied the friction-stir-welds (FSW) of Aluminum alloy AW6082-T6: In this paper the properties and micro-structural changes in friction stir welds in the aluminum alloy 6082-T6 in function of varying process parameters have been investigated.
Softening of the material in the weld nugget and heat affected zone was observed i.e. the hardness of both the heat affected zone and the weld nugget is lower than that of the base metal. Rodrigues D. M., et al. (2008) studied the influence of Friction Stir Welding Parameters on the Micro-structural and Mechanical properties of AA 6016T4 Thin Welds: In this present work friction stir welds produced in $1 \mathrm{~mm}$ thick plates of AA6016-T4 aluminum alloy, with two different tools, were analyzed and compared concerning the micro-structure and mechanical properties. Kim Y.G., et al. (2006) studied the effect of Welding Parameters on Microstructure in the Stir Zone of FSW Joints of Aluminum die Casting Alloy in this study the effect of the welding speed and the rotation speed on the microstructure in the stir zone has been investigated by measuring the Si particle distribution in the Aluminum die casting alloys which are made by the rapid injection of molten metal into metal molds under high pressure. Sato Y. S. \& Kokawa H. (2001) studied the distribution of Tensile Property and Microstructure in Friction stir Weld of 6063 Aluminum: The objective of the present study is to clarify dominant micro-structural factors governing the global tensile properties of the welded joint by estimation of the distribution of the local tensile properties in the joint including extensive regions from the stir zone to the unaffected base material region. In this study an extruded 6063-T5 Al, $4 \mathrm{~mm}$ thickness plates were friction stir welded keeping the travel speed and the tool shoulder diameter were $10 \mathrm{~mm} / \mathrm{s}$ and $15 \mathrm{~mm}$ respectively. Yeni $C$., et. al. (2008) studied the effect of Post Weld-aging on the Mechanical and Microstructural Properties of Friction-stir Welded Aluminum alloy 7075. It has been seen that left helical screw yields higher mechanical properties when tested at the same shoulder diameter.

The quality of welding joint highly depends on the process parameter. In the present investigation an attempt has been made to investigate the effect of optimum process parameters on mechanical properties and microstructural characteristics of the welded joint made from commercial aluminum alloy.

\section{FSW tool geometry}

From the survey of literature it was found FSW welding has been carried out by using complicated tool geometries, which are extremely difficult to manufacture. But it was observed that the complicated tool pin profiles tend to wear out after few numbers of runs leading to a conical form. This has been occurred specially while working with comparatively higher tensile strength materials, e.g. AA 7075-T651. Hence in the present work it was decided to study the performance of FSW tools having simple regular geometrical forms, like SC and TC. On prolonged usage, even if these tools wear down, they will attain tapered cylindrical or cylindrical shape. Therefore a systematic study of these regular simple geometrical shapes was taken up to study the mechanical and micro-structural properties of FSW welded sample.

In this present study SS310 have been used to fabricate the FSW tools. The material composition and the thermomechanical properties of SS 310 are shown in Tables 1 
and 2, respectively. The chosen tool geometries and the fabricated tool for FSW of $6 \mathrm{~mm}$ thick aluminum alloy are shown in Fig. 2 and Fig. 3 respectively.

Table 1 Composition of SS310 by percentage

\begin{tabular}{|l|l|l|l|l|l|l|l|}
\hline $\mathrm{Fe}$ & $\mathrm{C}$ & $\mathrm{Cr}$ & $\mathrm{Mn}$ & $\mathrm{Ni}$ & $\mathrm{P}$ & $\mathrm{S}$ & $\mathrm{Si}$ \\
\hline $\begin{array}{l}48- \\
53\end{array}$ & 0.25 & $\begin{array}{l}24- \\
26\end{array}$ & 2 & $19-22$ & 0.045 & 0.03 & 1.5 \\
\hline
\end{tabular}

Table 2 Physical properties of SS310

\begin{tabular}{|l|l|}
\hline Hardness, Brinell & 160 \\
\hline Tensile strength, ultimate $(\mathrm{MPa})$ & 655 \\
\hline Tensile strength, yield $(\mathrm{MPa})$ & 275 \\
\hline Thermal conductivity at $100 \mathrm{deg} \mathrm{C}\left(\mathrm{W} / \mathrm{m}^{2} \mathrm{~K}\right)$ & 14.2 \\
\hline
\end{tabular}

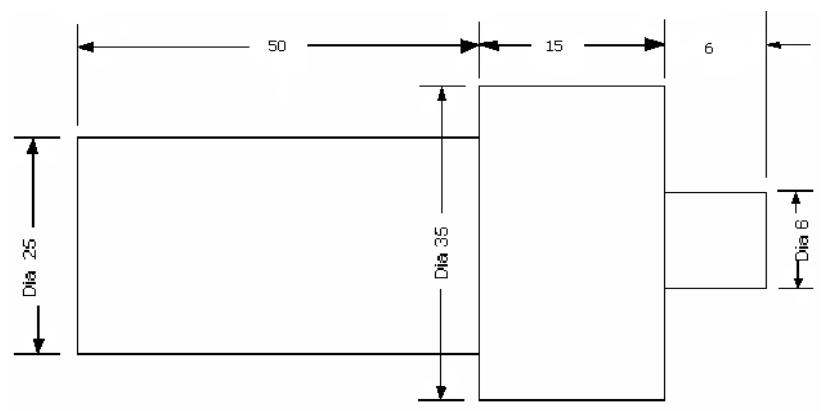

Fig. 2 Basic FSW tool geometry

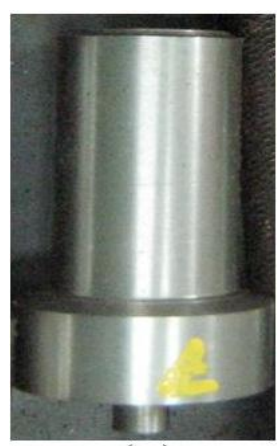

(a)

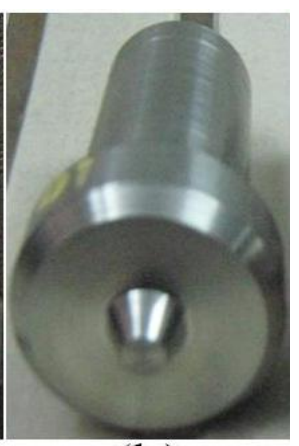

(b)
Fig. 3 Fabricated FSW tools (a)SC and (b) TC

\section{Experimental details}

To carry out the FSW experiment a vertical milling machine with $7.5 \mathrm{hp}$ motor capacity was used. The tool was mounted in the vertical arbor using a suitable collate. The plates to be joined were clamped to the horizontal bed with zero root gap. The clamping of the test pieces was done such that the movement of the plates was totally restricted under both plunging and translational forces of the FSW tool. The tool rpm and translational speed of the bed were set prior to each run of welding. After plunging the rotating tool at the plate butt and visually ensuring full contact of the tool shoulder with the plate surface, the bed movement was done. A typical experimental FSW setup is shown in Fig. 4.

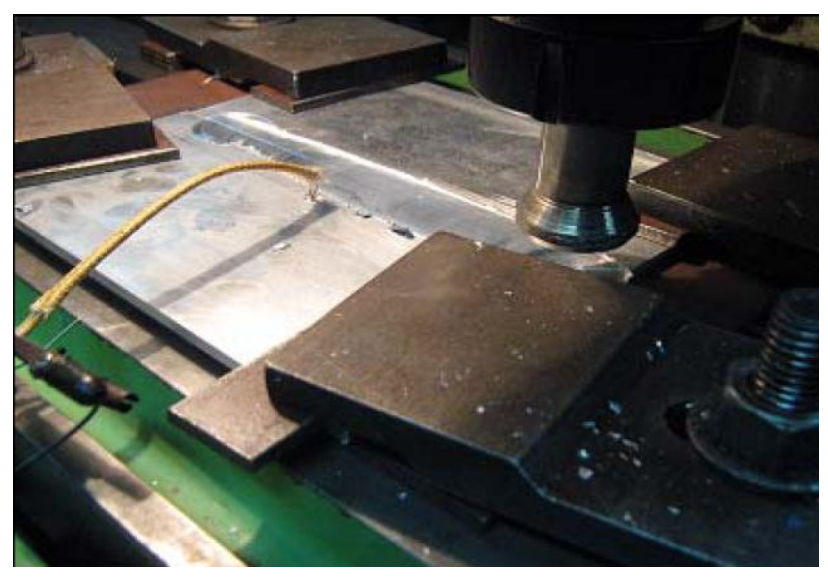

Fig. 4 FSW experimental setup

\section{Results and discussion}

Extensive FSW experiments were carried out to optimum the process parameter which give the good quality of welded joint by using the above designed tool geometry. From the experimental observation the optimum process parameters were decided which is shown in Table 3. The sample of FSW weld sample obtained by using above parameter is shown in Fig. 5.

Table 3: FSW Process parameters for of $6 \mathrm{~mm}$ thick aluminum alloy test samples

\begin{tabular}{|l|l|l|l|}
\hline $\begin{array}{l}\text { Sl. } \\
\text { No. }\end{array}$ & $\begin{array}{l}\text { Tool rotational } \\
\text { speed } \\
(\mathrm{rpm})\end{array}$ & $\begin{array}{l}\text { Tool transverse } \\
\text { speed } \\
(\mathrm{mm} / \mathrm{min})\end{array}$ & $\begin{array}{l}\text { Tool plunging } \\
\text { force } \\
(\mathrm{N})\end{array}$ \\
\hline 1 & 1400 & 112 & 6300 \\
\hline
\end{tabular}

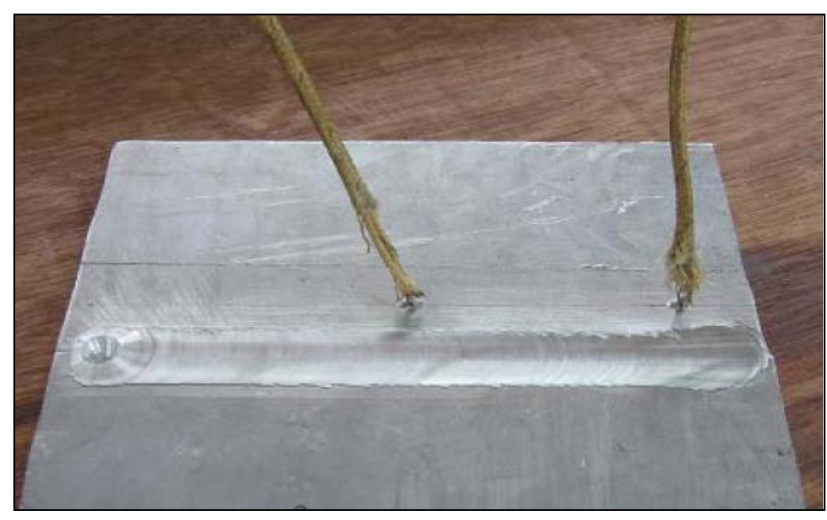

Fig. 5 FSW weld sample

The results of tensile testing, micro-hardness and microstructure have been described in three sub-sections below.

\subsection{Tensile testing}

The FSW welds cut according to the ASTM specifications for tensile testing are shown in Fig. 6. The tensile testing of the welds was done using a UTM machine and the load verses displacement graph has been obtained as shown in Fig 7 and Fig 8. 


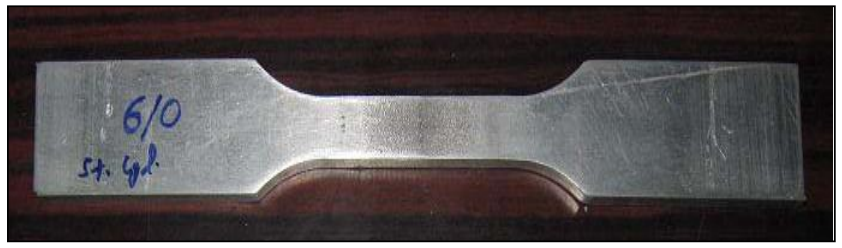

Fig. 6 Tensile Specimen

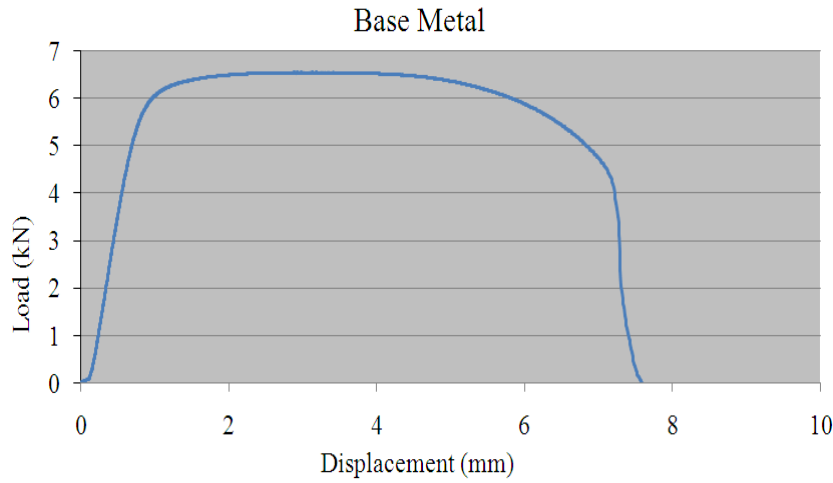

Fig. 7 Tensile test result for Base Metal

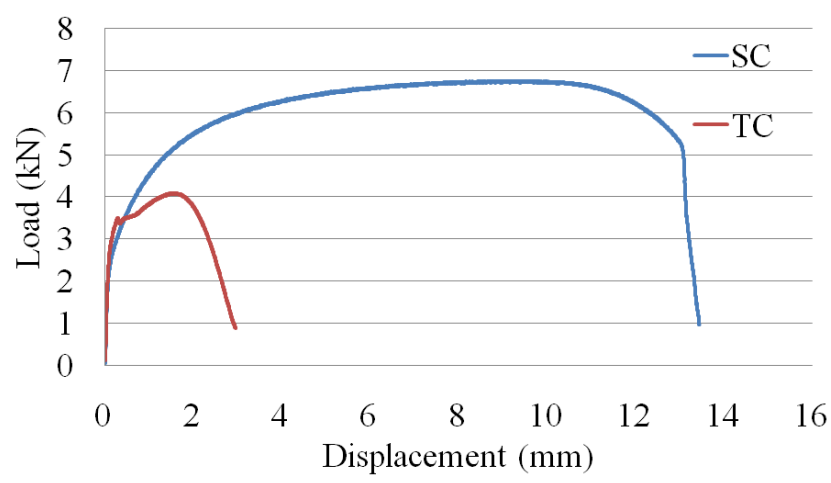

Fig. 8 Tensile test result for Welded Plates

The tensile testing results show that compared to base metal the tensile property of the weld improved considerably. Joints with SC tool shown better tensile properties compared to TC tool. This is due to the uniform mixing of material in case of SC tools. The ductility increased remarkably with the use of SC tool.

\subsection{Micro-hardness}

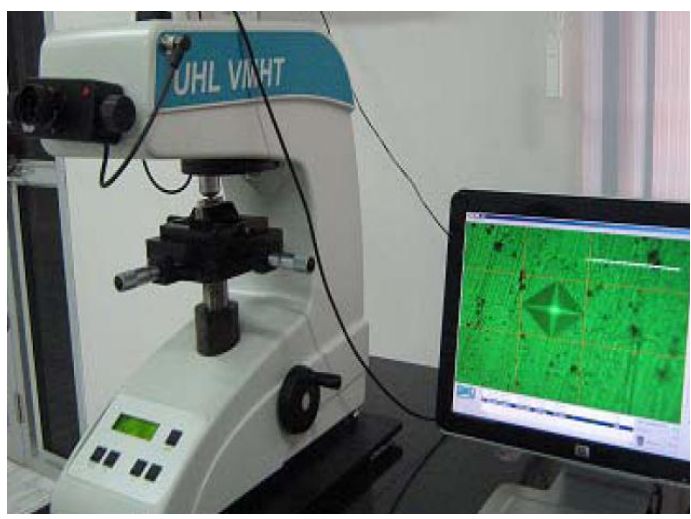

Fig. 9 Microhardness testing
The welded samples were tested for micro-hardness and measurements were taken on the cross sections perpendicular to the welding direction. A load of $100 \mathrm{gf}$ was kept for hardness measurement. The instrument used for the experiments is shown in the figure Fig 9. The microhardness of the weld zone and the heat affected zones were measured for the sample. The obtained microhardness trend is shown in Fig 10.

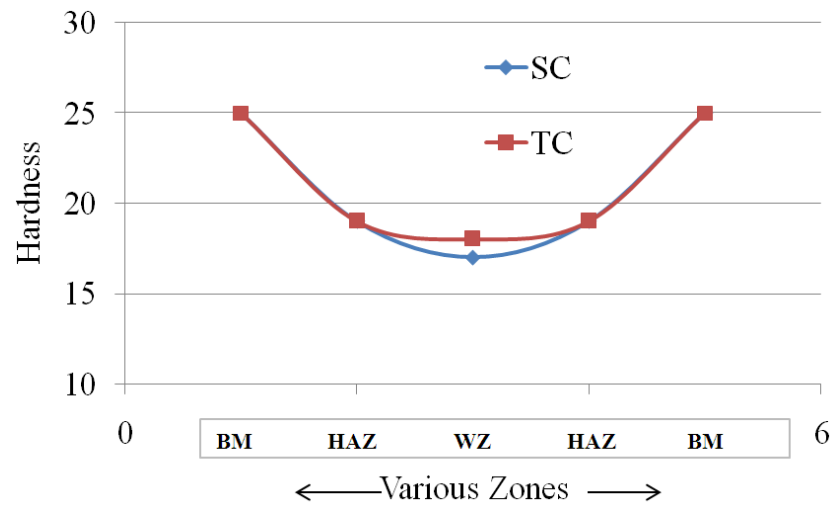

Fig. 10 Microhardness of FSW weld sample

It can be observed from the graph that the hardness values of the weld zone or the nugget is lower than the base materials. This indicates the improved ductility of the weld. And there is not much difference in the hardness values of weld zone (WZ) and heat affected zone (HAZ). Also there is no significant effect of tool geometry on hardness of the joints.

\subsection{Micro-structure}

Metallographic tests on the transverse cross sections of different welded samples were carried out to study the microstructures of different zones of the welded samples. The samples were thoroughly polished and then etched with Keller's reagent. An optical image analyzer (Leica) was used for this purpose as shown in Fig 11. The microstructure has been revealed and the grain size of the different zones of the welded sample was measured.

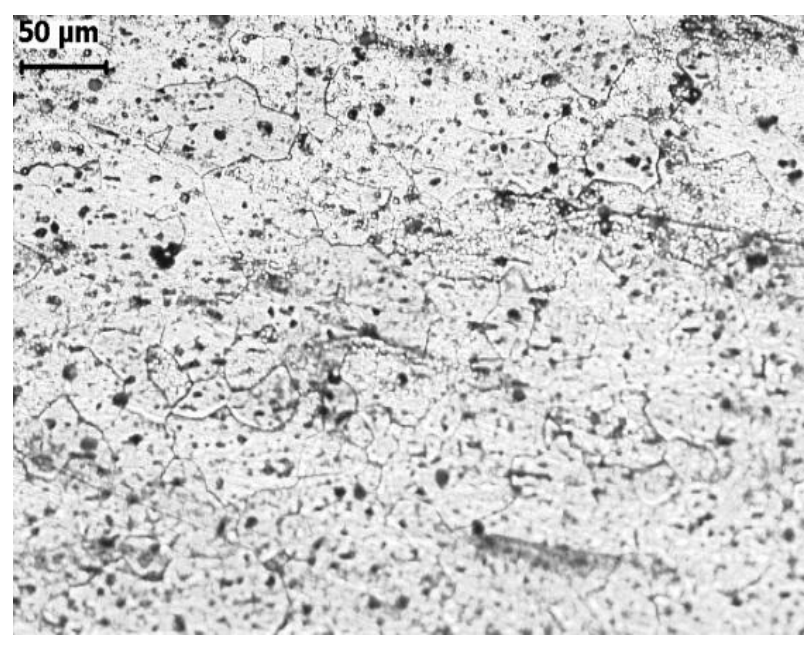

Fig. 11 Electron optical microscope 


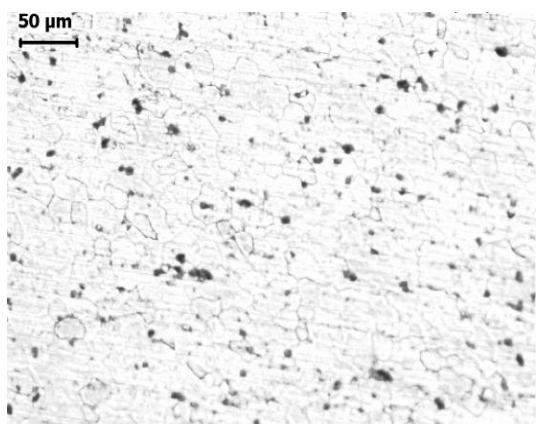

Fig. 12 Microstructure of HAZ

From the microstructural evolution it has been found that grain refinement occurs in FSW process. The grain sizes of different zones for different tool geometries were listed below in Table 4 .

Table 4 Average grain size for different zones

\begin{tabular}{|l|l|l|l|}
\hline \multirow{2}{*}{ Sl. No. } & \multirow{2}{*}{ Zones } & \multicolumn{2}{|l|}{ Average grain size $(\mu \mathrm{m})$} \\
\cline { 3 - 4 } & & $\mathrm{SC}$ & $\mathrm{TC}$ \\
\hline 1 & HAZ & 47.93 & 48.08 \\
\hline 2 & WZ & 30.41 & 37.62 \\
\hline
\end{tabular}

From the above table it can be seen that SC tool produced least size grains in WZ thus enhancing ductility remarkably.

\section{Conclusions}

In this work $6 \mathrm{~mm}$ thick commercial grade aluminum plates have been welded by using a $6 \mathrm{~mm}$ diameter SC and TC probe / pin FSW tool. From the above designed FSW tool geometry and the above process parameters a very good quality weld has been achieved by which the following conclusions can be made:

- The tensile strength of the weld is better than the parent material.

- In terms of strength and ductility SC tool shown better result than TC tools.

- The hardness values of the weld zone and HAZ are lower than the base material which indicates the improved ductility of the weld.

- No significant effect of tool geometry on hardness of different zones was found.

- From the micro-structural study it has been observed that the weld zone is stirred and having more grain refinement as compared to the HAZ zone.

- Due to uniform mixing of materials in the thickness direction the average grain size in $\mathrm{WZ}$ for the SC tool is lower which in turn indicates the higher ductility value.

The weld strength and quality of the weld obtained during the experiment indicated the success of the process.

\section{Acknowledgements}

The authors would like to thank Prof. (Dr.) N. R. Mandal
(OENA Dept., IIT Kharagpur) for many helpful discussions and their interest in this work.

\section{References}

Wang Dequing, Liu Shuhua, Study of Friction stir welding of aluminum, Journal of Materials Science Volume 39 (2004) 1689 - 1693.

L. Ceschini , I. Boromei,G. Minak, A. Morri, F. Tarterini, Microstructure, tensile and fatigue properties of AA6061/20 vol.\%A12O3p friction stir welded joints, Elsevier Science Ltd., Part A 38 (2007) 1200-1210.

Moataz M. Attallah, Claire L. Davis, Martin Strangwood, Microstructuremicrohardness relationships in friction stir welded AA525, Journal of Material Science, (2007) 42:7299-7306 DOI 10.1007/s10853-007-1585-y.

G.M. Xie, Z.Y. Ma, L. Gengb, R.S. Chen, Microstructural evolution and mechanical properties of friction stir welded $\mathrm{Mg}-\mathrm{Zn}-\mathrm{Y}-\mathrm{Zr}$ alloy, Material Science and Engineering, Volume A471 (2007) 63-68.

Scialpi, L.A.C. De Filippis, P. Cavaliere, Influence of shoulder geometry on microstructure and mechanical properties of friction stir welded 6082 aluminum alloy, Journals for Materials and Design, Volume 28 (2007) 1124-1129 DOI:10.1016/j.matdes.2006.01.031.

Hidetoshi Fujii, Ling Cui, Masakatsu Maeda, Kiyoshi Nogi, Effect of tool shape on mechanical properties and microstructure of friction stir welded aluminum alloys , Journal of Material Science and Engineering, Volume A 419 (2006),Pages 25-31.Mustafa Boz, Adem

Kurt, The Influence of Stirrer Geometry on Bonding and Mechanical Properties in friction stir welding process, Journal of Materials and Design, Volume 25 (2004), Pages 343-347.

R. W. Fonda, K. E. Knipling and J. F. Bingert, Microstructural evolution ahead of the tool in Al friction stir welds, Scripta Materialia 58 (2007) 343-348.

A.Simar, Y. Br'echet, B. de Meester, A. Denquin, T. Pardoen, Microstructure, local and global mechanical properties of friction stir welds in aluminium alloy 6005A-T6, Material Science and Engineering, A 486 (2008) 85-95.

M. Cabibbo, H.J. McQueenb, E. Evangelista, S. Spigarelli, M. Di Paola, A. Falchero, Microstructure and mechanical property studies of AA6056 friction stir welded plate, Journal of Materials Science and Engineering, Volume A 460-461 (2007), Pages 86-94.

Furkan Sarsilmaz - Ulas caydas, Statistical Analysis on Mechanical Properties of Friction Stir Welded AA1050/AA5083 couples, International Journal of Advanced Manufacturing Technology (2008), DOI 0.1007/s00170-0081716-x.

T Sakthivel, G S Senegar, J Mukhopadhyay, Effect of Welding Speed on Micro-structure and Mechanical Properties of Friction-stir Welded Aluminum, International Journal of Advanced Manufacturing Technology (2008), DOI 10.1007/s00170-008-1727-7.

J. Adamowski, M Szkodo, Friction-stir-welds (FSW) of Aluminum alloy AW6082-T6 , Journal of Achievements in materials and Manufacturing Engineering, Volume 20, Issue 1-2, January-February 2007.

D M Rodrigues, A Loureiro, C Leitao, R M Leal, B M Chaparro, P Vilaca, Influence of Friction Stir Welding Parameters on the Micro-structural and 79 Mechanical properties of AA 6016-T4 Thin Welds, Journals for Materials and Design (2008), DOI 10.1016/j.matdes.2008.09.016.

Y.G. Kim, H. Fujii, T. Tsumura, T. Komazaki, K. Nakata, Effect of Welding Parameters on Microstructure in the Stir Zone of FSW Joints of Aluminum die Casting Alloy, Journals for Materials Letters Volume 60 (2006) 3830 3837 DOI:10.1016/j.matlet.2006.03.123.

Yutaka S Sato and Hiroyuki Kokawa, Distribution of Tensile Property and Micro-structure in Friction stir Weld of 6063 Aluminum, Metallurgical and Materials Transactions, Volume 32A, December 2001-3023.

C Yeni, S sayer, O Ertugrul, M Pakdil, Effect of Post Weld-aging on the Mechanical and Micro-structural Properties of Friction-stir Welded Aluminum alloy 7075, Achieves of Material Science and Engineering, Volume 34, Issue 2, December 2008, Pages 105-109.

J. corneli, V.Ettinger, W. Baumgart, (2004), Thermal analysis , an Unique Fingerprint of a melt ,66th World Foundry Congress 6-9 , pp. 743-756.

Seidu, S.O (2008). Influence of Inoculant's type on thermal analysis parameters of ductile irons, $4^{\text {th }}$ internaltion conference, Galati, Romania, pp. 237-241.

M. Chisamera, S. Stan, I. Riposan, E. Stefan, G. Costache, (2007), Thermal analysis of Inoculated Grey Cast Irons, UGALMAT,Galati,TechnologiisiMaterialeAvansate,University press, Vol.1, pp.17-23.

Seidu, S.O., Riposan, I, (2011), Thermal analysis of inoculated ductile irons University Politehnica of Bucharest Scientific. Bulletin, Series B, Vol. 73, Iss.2, Romania

Y. Gunay, S.Decirmenci, I. Metan, B. Sirin, (2004), The Application of Adaptive Thermal Analysis System (ATAS) on Grey and Ductile Iron Production, $66^{\text {th }}$ World Foundry Congress, 06-09.09., Istanbul, Turkey. 